\title{
Assessment of programmed death-ligand 1 receptor immunohistochemical expression and its association with tumor-infiltrating lymphocytes and p53 status in triple-negative breast cancer
}

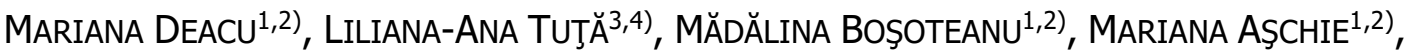 \\ AnCA Florentina Mitroi ${ }^{1,5)}$, ANTONELA-ANCA NiCOlaU ${ }^{1,5)}$, MANUELA ENCIU ${ }^{1,2}$, \\ OANA COJOCARU ${ }^{1,2)}$, LUCIAN CRISTIAN PETCU ${ }^{1,6)}$, GABRIELA IZABELA BĂLTĂTESCU ${ }^{1,5}$ \\ 1) Clinical Service of Pathology, Sf. Apostol Andrei Emergency County Hospital, Constanta, Romania \\ 2) Department of Pathology, Faculty of Medicine, Ovidius University of Constanta, Romania \\ 3) Department of Nephrology, Sf. Apostol Andrei Emergency County Hospital, Constanta, Romania \\ 4) Department of Nephrology, Faculty of Medicine, Ovidius University of Constanţa, Romania \\ ${ }^{5)}$ Center for Research and Development of the Morphological and Genetic Studies of Malignant Pathology \\ (CEDMOG), Ovidius University of Constanta, Romania \\ 6) Department of Biostatistics \& Biophysics, Faculty of Dental Medicine, Ovidius University of Constanta, \\ Romania
}

\begin{abstract}
Breast cancer $(B C)$ is the second most frequent type of cancer for both sexes combined, after lung cancer. Triple-negative BC (TNBC) molecular subtype is characterized by lack of estrogen receptor (ER), progesterone receptor (PR) and human epidermal growth factor receptor 2 (HER2) immunoexpression or amplification and represent $10-20 \%$ of all BC cases. The issue of the present study was to analyze the associations between programmed death-ligand 1 (PD-L1) immunoexpression and distribution of stromal tumor-infiltrating lymphocytes (stTILs) combined with clinico-morphological features of patients with TNBC. Secondly, our research evaluated PD-L1 immunoexpression as a prognostic factor and its correlation with p53 immunoexpression. Thirty cases with primary TNBC without prior neoadjuvant therapy were included in this research. stTILs were identified in all cases, most of them with low distribution (66.7\%). A positive immunoreaction for PD-L1 was observed in 40\% of cases. The PD-L1 immunoexpression was statistically significant associated with age, pathological tumor size, lymphovascular invasion, stTILs level, the presence of cluster of differentiation 8-positive (CD8+) TILs and p53 immunoexpression. In the present study, a positive PD-L1 immunoexpression was associated with a worse distant metastasis free survival (DMFS). We also found not only that high stTILs level were associated with a better DMFS but also that there was a statistically significant association between stTILs level and PD-L1 immunoexpression. Our results bring new insights to the fine connections between tumor microenvironment and molecular changes of TNBC. It helps us to better understand these aggressive tumors to identify the more useful biomarkers for predicting the response to adjuvant therapy and can represent a method for selecting the most suitable patients for immunotherapy.
\end{abstract}

Keywords: triple-negative breast cancer, immunohistochemistry, PD-L1, tumor-infiltrating lymphocytes, p53.

\section{a Introduction}

Breast cancer $(\mathrm{BC})$ is the second most frequent type of cancer for both sexes combined, after lung cancer, with a $16.6 \%$ incidence worldwide, according to Bray et al. (2018) [1]. In the last two decades, numerous studies highlighted the huge heterogeneity of the $\mathrm{BC}$ and tailor therapies were developed to improve the survival and quality of life for these patients. Despite of all efforts, $\mathrm{BC}$ continues to be the leading cause of death in female population in more than 100 countries, with $15 \%$ mortality rate worldwide [1]. From the first molecular classification of BC realized by Perou et al. in 2000 [2] and Sørlie et al. in 2001 [3], huge progresses have been done in understanding the molecular biology of different morphological subtypes of $\mathrm{BC}$ and four molecular surrogate subtypes of $\mathrm{BC}$ emerged at the St. Gallen Consensus in 2013, with different therapeutic and prognostic implications: luminal A-like, luminal B-like, human epidermal growth factor receptor 2 (HER2)-positive and triple-negative BC (TNBC). Their definition is based on the immunoexpression of estrogen receptor (ER) and progesterone receptor (PR), proliferation rate and immunoexpression or amplification of HER2 [4].

TNBC subtype is characterized by lack of ER, PR and HER2 immunoexpression or amplification and represents $10-20 \%$ of all BC cases [5]. But this category of BCs is not a simple one and, in fact, it is extremely heterogeneous. It includes different morphological subtypes of $\mathrm{BC}$, and it is associated with variable prognosis. Most of them have an aggressive clinical behavior comparing with the other subtypes. The heterogeneity of TNBC is under the debate of several studies, which try to characterize it furthermore, to unravel new potential therapeutic agents 
which can improve the overall survival (OS). A special attention is paid to immune microenvironment of the tumors and tumor-infiltrating lymphocytes (TILs) emerge as a biomarker for the immunogenicity of BC. High value of TILs is associated with an improvement of diseasefree survival (DFS) and OS in TNBC, and it can be used as a strong prognostic factor [6-8]. The composition of TILs is complex, $75 \%$ of TILs are represented by T-lymphocytes, most of them being cluster of differentiation (CD) $8+$ (cytotoxic T-lymphocytes) and secondly CD4+ (T-helper cells) [9].

One way of the malignant cell to escape from immune defense is through the axis of programmed death 1 (PD1) receptor and its ligand [programmed death-ligand 1 (PD-L1)]. PD1 receptor, known also as "checkpoint molecule", is expressed mainly on the mononuclear inflammatory cells and its activation by PD-L1 or PD-L2 ligands acts as a "brake" for the immune response [10]. Therapy with immune checkpoint inhibitors (ICIs) not only proved its efficacy in several aggressive cancers, like melanoma or non-small cell lung carcinoma, but recently is considered as a therapeutic option for metastatic or locally advanced TNBC [11].

\section{Aim}

The aim of the present study was to analyze the associations between PD-L1 immunoexpression and distribution of stromal TILs (stTILs) in conjunction with clinico-morphological features of patients with TNBC from a single institution in southeastern of Romania. The second objective was to evaluate the value of PD-L1 immunoexpression as a prognostic factor and its correlation with p53 immunoexpression.

\section{ㅁ Patients, Materials and Methods}

\section{Patient cohort}

In the present study, cases were selected from the recoded medical data and electronic database of the Department of Clinical Pathology between 2014 and 2018. We identified all the patients clinically diagnosed with BC in the Department of Surgery of our Hospital, which proved to be ER/PR negative and with a HER2/neu negative status evaluated by immunohistochemistry (IHC) or/and by chromogenic in situ hybridization (CISH). All these cases were reviewed according to internal protocol of the Department of Clinical Pathology based on criteria of World Health Organization (WHO) breast tumor [12] and recommendations of St. Gallen Consensus, to establish molecular surrogate subtypes [4]. Thirty cases with primary TNBC without prior neoadjuvant therapy were included in this research. Clinico-morphological features were taken from pathological file of the patients including: age at the time of diagnosis, type of surgery, tumor size, morphological type of $\mathrm{BC}$, tumor grade, the presence of in situ component, lymphovascular invasion, lymph node status, presence or absence of distant metastasis and type of adjuvant therapy followed by the patient after surgical intervention. It has been also recorded the date when distant metastases had been identified and the last date of follow-up, both criteria being useful for survival analysis. Incomplete clinical data or preoperative neoadjuvant therapy were considered as exclusion criteria. A written consent signed by each patient included in our study was available.

\section{TILs evaluation}

TILs evaluation was performed on usual HematoxylinEosin (HE) whole stained slides according to the Guidelines established by the International TILs Working Group 2014 [13] by a trained pathologist on scoring TILs using the available on-line resource $[13,14]$. A semiquantitative analysis of stTILs was performed as a continuous parameter (increment of $10 \%$ ). The percentage of stTILs was defined by the average area occupied by all mononuclear inflammatory cell over total intra-tumoral connective tissue stroma, which was considered the adjacent area to invasive tumor [13]. For statistical analyses, it was further stratified in categorical variable in which absent or focal stTILs if $<10 \%$, low stTILs if the score was $\geq 10 \%-<50 \%$ and high stTILs if $\geq 50 \%$ [15].

\section{Immunohistochemical staining and evaluation}

The most representative formalin-fixed and paraffinembedded blocks were sectioned $4 \mu \mathrm{m}$ thick and followed the immunostaining protocol for manual method. Incubation of slides was done using the following ready-to-use, primary antibodies from Master Diagnóstica (Granada, Spain): rabbit anti-human PD-L1 monoclonal antibody (clone CAL10); rabbit anti-human p53 monoclonal antibody (clone SP5); rabbit anti-human CD8 monoclonal antibody (clone SP16). Master Polymer Plus Detection System, which include 3,3'-Diaminobenzidine (DAB) chromogen, was used for detection and brown staining of antigen concerned. The final step consisted in counterstaining with Mayer's Hematoxylin and mounting the slides. Tonsil was used as positive control for PD-L1 and CD8 biomarkers and serous carcinoma of the ovary as positive control for p53 assessment. HER2 status was reviewed using the recommendations of American Society of Clinical Oncology/College of American Pathologists (ASCO/CAP) 2018 [16].

\section{Statistical analysis}

In the current research, Statistical Package for the Social Sciences version 20.0 (SPSS Inc.; Chicago, IL, USA) software was used for data recording and statistical analysis. Each data was labeled as either nominal or quantitative variable. A descriptive statistic was performed for quantitative variables. Comparisons of ratios in independent groups were performed with $\chi^{2}$ (chi-squared) test. Kaplan-Meier method was applied to obtain the cumulative percentages of distant metastasis free survival (DMFS) time followed by log-rank tank test for further analyze. DMFS was defined as the time from initial diagnose to the time of distant metastasis. Those cases without distant metastases or those cases in which the follow-up had been lost before the established period of two years, were labeled as censored. A two-tailed $p$-value $<0.05$ was considered significant.

\section{a Results}

Thirty female patients were included in current study, with a mean age of $62.47 \pm 11.649$ years (from 43 to 84 years), from which $73.3 \%$ were more than 50 years old. Most of the patients underwent radical mastectomies \pm 
regional lymphadenectomy, with a mean tumor diameter $42 \pm 34.482 \mathrm{~mm}(10-180 \mathrm{~mm})$ and $16.7 \%$ of them were multifocal tumors. Regarding the morphological type, we observed a high prevalence for invasive ductal carcinomanot otherwise specified (IDC-NOS) in our group (80\%) and the remaining were represented by three cases of IDC with medullary features (Figure 1, A-D), one case of IDC with sebaceous differentiation, and one case with inflammatory BC. High histopathological grade was recorded in $63.4 \%$ of our cohort, most of them $(75 \%)$ having also a positive reaction for PD-L1 (Figure 2). An intraductal component was observed in $66.7 \%$ of cases and lymphovascular invasion was noted within 15 cases. stTILs were identified in all cases, with mean $44 \pm 22.984$, most of them with low distribution (66.7\% of cases). According to the American Joint Committee on Cancer (AJCC) tumor stages, we observed that pT2 was the most frequent one (40\%) followed by pT3 and pT4, each with six cases. The mean time of follow-up was 16.2 \pm 7.286 months (range 2-24 months).
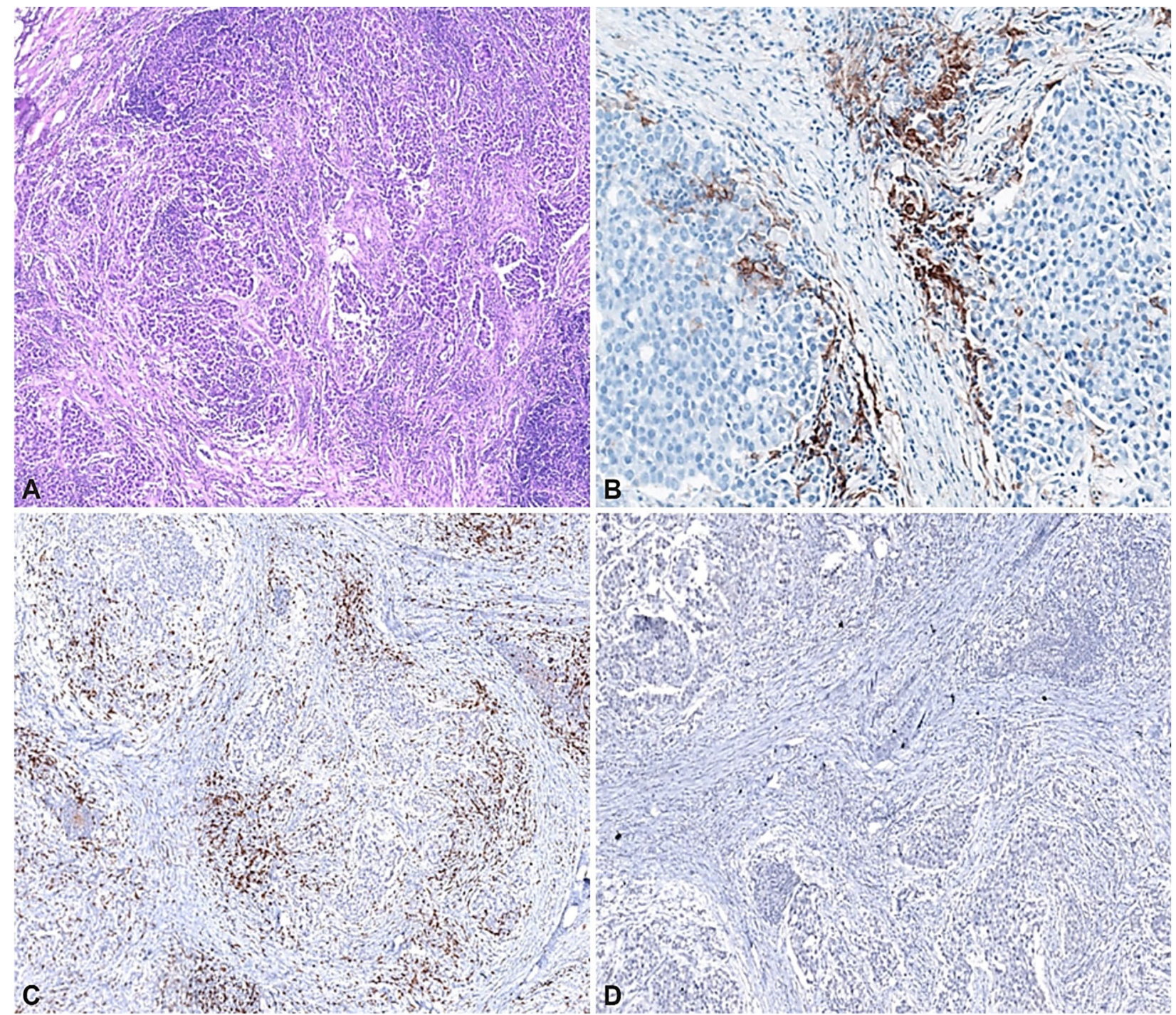

.

Figure 1 - Representative morphological and IHC features of a TNBC, IDC with medullary architecture: (A) High stTILs level (HE staining, $\times 100)$; (B) Positive membranous immunostaining for anti-PD-L1 antibody in more than $1 \%$ of immune cells adjacent to tumor cells (IHC, $\times 200)$; (C) Positive nuclear immunostaining for CD8 TILs in more than 10\% of tumor cells (IHC, ×40); (D) "Null-type" immunoexpression for p53 (IHC, ×40). CD8: Cluster of differentiation 8; HE: Hematoxylin-Eosin; IDC: Invasive ductal carcinoma; IHC: Immunohistochemistry; PD-L1: Programmed deathligand 1; stTILs: Stromal tumor-infiltrating lymphocytes; TNBC: Triple-negative breast cancer.

We analyzed the pattern of distribution and the percentage of positive cells for each antibody. A positive immunoreaction for PD-L1 was considered when $>1 \%$ of mononuclear inflammatory cells from the stromal compartment or/and tumor cells are membranous stained [17] and it was observed in $40 \%$ of cases, from which $58.3 \%$ were positive in only stTILs (Figure 1B) and $16.7 \%$ positive only in tumor cells. A simultaneous positive immunostaining of both compartments was identified in 11 cases (Figure 2B).
Associations between PD-L1 immunoexpression and the main clinico-pathological and IHC features of the cases included in our study are detailed in Table 1.

The most statistically significant associations were represented by age more than 50 years old ( $p=0.018$ ), pathological tumor size $(p=0.025)$, lymphovascular invasion $(p=0.025)$, stTILs level $(p=0.018)$, the presence of CD8+ TILs $(p=0.004)$, and p53 immunoexpression $(p=0.044)$ (Table 1). 
Table 1 - Clinico-pathological features of TNBC according to PD-L1 immunoexpression

\begin{tabular}{|c|c|c|c|c|}
\hline $\begin{array}{c}\text { Clinico-pathological } \\
\text { features }\end{array}$ & $\begin{array}{c}\text { PD-L1 } \\
\text { negative } \\
n(\%) \\
\end{array}$ & $\begin{array}{c}\text { PD-L1 } \\
\text { positive } \\
n(\%)\end{array}$ & $\begin{array}{c}X^{2} \\
\text { score }\end{array}$ & $\begin{array}{c}p- \\
\text { value }^{*}\end{array}$ \\
\hline Total cases & $18(60.0 \%)$ & $12(40.0 \%)$ & & \\
\hline Age [years] & & & 5.568 & 0.018 \\
\hline$\leq 50$ & $2(11.1 \%)$ & $6(50.0 \%)$ & & \\
\hline.$>50$ & $16(88.9 \%)$ & $6(50.0 \%)$ & & \\
\hline Morphological type & & & 0.139 & 0.709 \\
\hline - IDC-NOS & $14(77.8 \%)$ & $10(83.3 \%)$ & & \\
\hline - Others & $4(22.2 \%)$ & $2(16.7 \%)$ & & \\
\hline Tumoral grade (G) & & & 1.172 & 0.279 \\
\hline G2 & $8(44.4 \%)$ & $3(25.0 \%)$ & & \\
\hline - G3 & $10(55.6 \%)$ & $9(75.0 \%)$ & & \\
\hline$D C / S$ & & & 0.625 & 0.429 \\
\hline - Yes & $13(72.2 \%)$ & $7(58.3 \%)$ & & \\
\hline - No & $5(27.8 \%)$ & $5(41.7 \%)$ & & \\
\hline $\begin{array}{l}\text { Pathological tumor size } \\
\text { (pT) }\end{array}$ & & & 5.000 & 0.025 \\
\hline pT1-pT2 & $12(66.7 \%)$ & $3(25.0 \%)$ & & \\
\hline - pT3-pT4 & $6(33.7 \%)$ & $9(75.0 \%)$ & & \\
\hline $\begin{array}{l}\text { Pathological lymph } \\
\text { node status }(p N)\end{array}$ & & & 2.738 & 0.098 \\
\hline$:<3$ & $10(55.6 \%)$ & $3(25.0 \%)$ & & \\
\hline$: \geq 3$ & $8(44.4 \%)$ & $9(75.0 \%)$ & & \\
\hline $\begin{array}{l}\text { Lymphovascular } \\
\text { invasion }\end{array}$ & & & 5.000 & 0.025 \\
\hline - No & $12(66.7 \%)$ & $3(25.0 \%)$ & & \\
\hline - Yes & $6(33.3 \%)$ & $9(75.0 \%)$ & & \\
\hline stTILs level & & & 5.625 & 0.018 \\
\hline . $<50 \%$ & $9(50.0 \%)$ & $11(91.7 \%)$ & & \\
\hline : $\geq 50 \%$ & $9(50.0 \%)$ & $1(8.3 \%)$ & & \\
\hline CD8 TILs & & & 8.167 & 0.004 \\
\hline - Negative (CD8- TILs) & $4(22.2 \%)$ & $9(75.0 \%)$ & & \\
\hline - Positive (CD8+ TILs) & $14(77.8 \%)$ & $3(25.0 \%)$ & & \\
\hline Ki67 status & & & 1.118 & 0.290 \\
\hline - Low Ki67 index & $3(16.7 \%)$ & $4(33.4 \%)$ & & \\
\hline - High Ki67 index & $15(83.3 \%)$ & $8(66.7 \%)$ & & \\
\hline p53 immunoexpression & & & 4.043 & 0.044 \\
\hline - p53 nonmutated & $14(73.7 \%)$ & $5(26.3 \%)$ & & \\
\hline - p53 mutated & $4(36.4 \%)$ & $7(63.6 \%)$ & & \\
\hline Metastatic relapse & & & 15.648 & $<0.001$ \\
\hline - No & $16(88.9 \%)$ & $2(16.7 \%)$ & & \\
\hline - Yes & $2(11.1 \%)$ & $10(83.3)$ & & \\
\hline
\end{tabular}

CD8: Cluster of differentiation 8; DCIS: Ductal carcinoma in situ; IDCNOS: Invasive ductal carcinoma-not otherwise specified; $n$ : No. of cases; PD-L1: Programmed death-ligand 1; stTILs: Stromal tumorinfiltrating lymphocytes; TNBC: Triple-negative breast cancer. ${ }^{*} \mathrm{Chi}-$ squared test.

A membranous staining of the stTILs in more than $10 \%$ of cells was considered the cutoff for a positive immunoreaction to CD8 biomarker [18] and it was recorded for $56.7 \%$ of all cases (CD8+ TILs) (Figures 1C and 2C). It was observed only three cases with CD8+ TILs from those which had also a positive immunostaining for PD$\mathrm{L} 1$, but a higher rate $(77.8 \%)$ was noticed in the PD-L1 negative category. A positive immunostaining for $\mathrm{p} 53$ was consider when the nuclei were brown-stained, and $10 \%$ value was considered as the cut-off point [19]. The intensity and distribution of p53 immunostaining was also analyzed: "null-type" - no nuclear staining; "wild-type" - weakly and focal brown nuclear staining; "overexpression" - strong and diffuse nuclear staining [20]. An aberrant p53 protein immunoexpression ("null-type" and "overexpression" type) was observed in $36.7 \%$ of cases, from which $63.6 \%$ were "overexpression" type (Figure 2D). The vast majority of those cases with an "overexpression" pattern $(85.7 \%)$ were noticed in the CD8+ TILs category. Ki67 index was reassessed using criteria of the St. Gallen Consensus 2015, in which a $20 \%$ value was recommended as a cut-off value for low/high level of proliferate tumoral rate [21]. Median value for Ki67 index was 60, interquartile range (IQR) $(30-80)$, most of the tumors having a high proliferation rate (76.7\%). Most of the tumors with an immunopositive reaction for PD-L1 were associated with a high Ki67 index $(66.7 \%)$.

PD-L1 immunoexpression proved to have a significant influence on DMFS, analyzed by Kaplan-Meier method and log-rank test, with $p<0.0001$ [PD-L1 negative: mean 22.471, 95\% confidence interval (CI): 20.473-24.468; PD-L1 positive: mean 11.375, 95\% CI: 7.788-14.962] (Figure 3A). A statistically significant differences regarding DMFS was also observed for stTILs values with an improvement for high values of stTILs, $p=0.014$ (low stTILs: mean 15.359, 95\% CI: 11.872-18.846; high stTILs: mean 22.800, 95\% CI: 20.569-25.031) (Figure 3B). A CD8+ TILs also had a statistically significant positive effect on MDFS with $p<0.001$ (CD8- TILs: mean 12.215, 95\% CI: 8.247-16.184; CD8+ TILs: mean 21.765, 95\% CI: 19.462-24.068) (Figure 3C). The p53 status (mutational and non-mutational) has also an impact on DMFS with $p=0.010$ (p53 non-mutated: mean 20.659, 95\% CI: 17.702 23.617; p53 mutated: mean 13.727, 95\% CI: 9.495-17.960) (Figure 3D).

\section{ㅁ Discussions}

TNBC is a relatively rare type of molecular subtype of $\mathrm{BC}$, which is associated with a poor prognosis. Its morphological features and molecular changes make it difficult to treat, being responsible for up to $25 \%$ of $\mathrm{BC}$ deaths [22]. Because it is not responsive to hormonotherapy or to the Trastuzumab, chemotherapy and radiotherapy are the only accepted possibilities as an adjuvant therapy for these patients.

Immunotherapy is a new approach to treat tumors which are highly "immunogenic" (tumors who have the capacity to induce host adaptive immunity). ICIs can have a negative impact on tumor progression and huge successes were obtained when this new form of therapy was approved and administrated in a variety of malignancy, resulting in great improvements of DFS and OS [23, 24]. Starting from this point, which it was considered a "breakthrough of the year 2013" [25], a special attention was paid to the distribution and quantity of immune infiltrate through different morphological subtype of BC. In 2019, a big step was done by obtaining the approval of Atezolizumab (an ICI drug which target the PD-L1) as adjuvant therapy for advance or metastatic TNBC, secondary to the results obtained by IMpassion130, a phase III trial $[11,26]$. Nevertheless, less than half of patients will benefit from immunotherapy [27] and further studies are necessary to refine those biological factors which can be used as predictive and prognostic factors. 

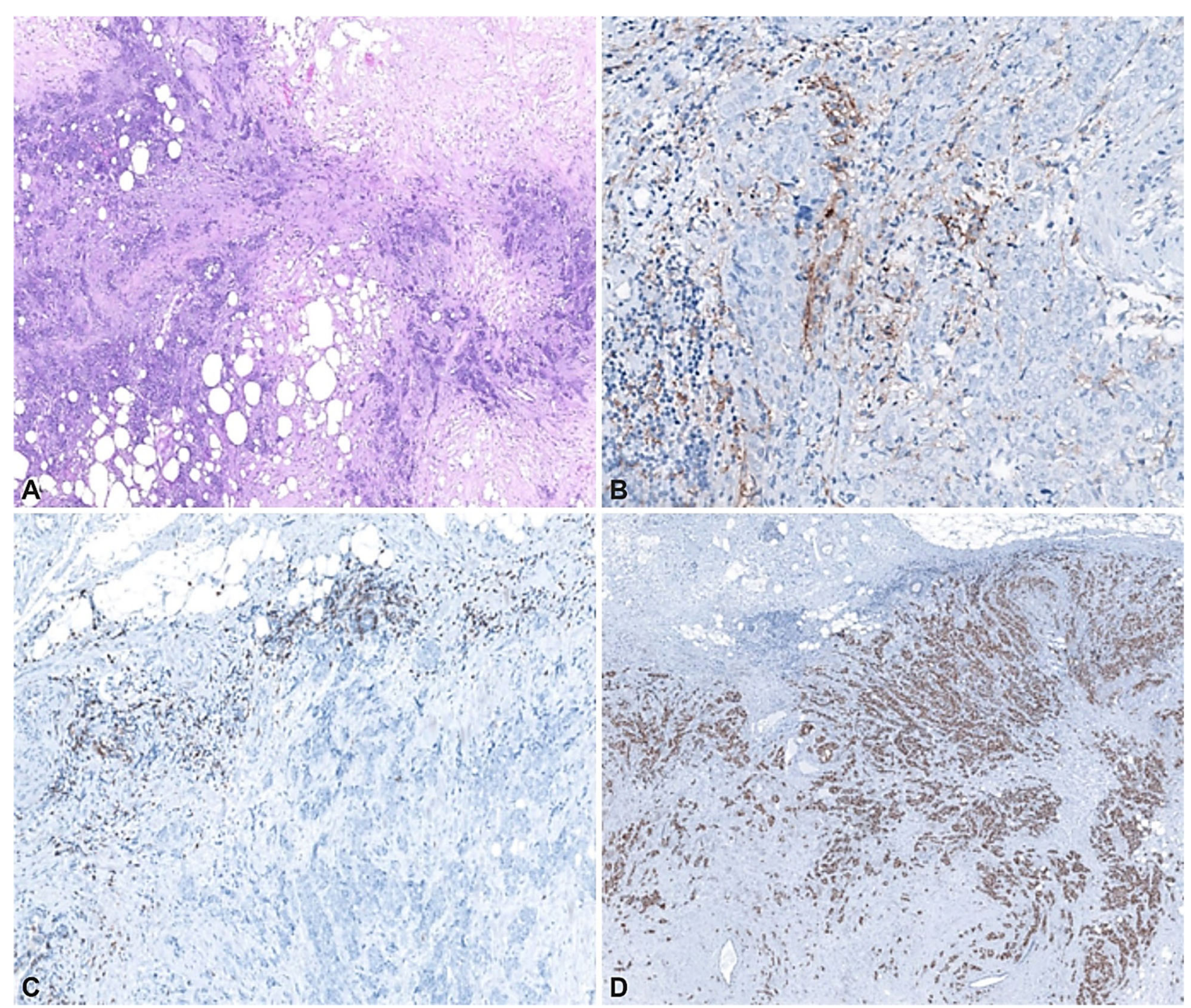

Figure 2 - Representative morphological and IHC features of a TNBC, IDC-NOS, poorly differentiated G3: (A) Low stTILs level (HE staining, $\times 100)$; (B) Positive membranous immunostaining for anti-PD-L1 antibody in more than $1 \%$ of immune cells and tumor cells (IHC, $\times 200)$; (C) Positive nuclear immunostaining for CD8 TILs in more than 10\% of tumor cells (IHC, ×40); (D) “Overexpression" immunostaining for p53 (IHC, ×40). CD8: Cluster of differentiation 8; HE: Hematoxylin-Eosin; IDC-NOS: Invasive ductal carcinoma-not otherwise specified; IHC: Immunohistochemistry; PD-L1: Programmed death-ligand 1; stTILs: Stromal tumor-infiltrating lymphocytes; TNBC: Triple-negative breast cancer.

In our study, we identified $40.0 \%$ of cases positive for PD-L1 in more than $1 \%$ of either tumor cells or stromal inflammatory cells. Differences between PD-L1 immunoexpression and clinico-morphological features were analyzed, and we observed a statistically significant differences with age ( $\leq>>50$ years old), a positive PD-L1 immunoexpression being associated with less than 50 years old. In the research of Zeng et al. (2019), which included 132 cases of TNBC, it was also observed statistically significant association with age, but a PD-L1 immunopositive tumors were more frequent associated with more than 50 years old, and no association with menopausal status [22]. In concordance with literature, the most predominant morphological type was represented by IDC-NOS, with no statistically significant differences between PD-L1 positive and PD-L1 negative group [22]. The same result was observed for "in situ" component, which was identified in $58.3 \%$ of PD-L1 positive cases. All ductal carcinoma in situ (DCIS) had not HER2/neu immunoexpression, having a perfect concordance with the invasive component, as it was previously reported [28]. Even if some researches proved to be an association between PD-L1 immunoexpression and tumoral grade or tumor proliferation rate, our study showed no statistically significant differences between PD-L1 positive and PD-L1 negative group, both being characterized by high rates of poorly differentiated tumors and high Ki67 index. We recorded a positive correlation for tumor diameter, the presence of lymphovascular invasion and the present of metastasis in more than three loco-regional lymph nodes (Table 1), similar with other studies [29, 30].

In the present study, a positive PD-L1 immunoexpression is associated with a worse DMFS. This result is in concordance with data from the literature which also emphasized the negative impact of PD-L1 immunoexpression over the DMFS in previous untreated patients $[22,31$, 32]. But not all the studies had the same results as there are reports which had shown a better survival if there is high ( $>10 \%)$ PD-L1 immunoexpression on tumor cells $[33,34]$. 

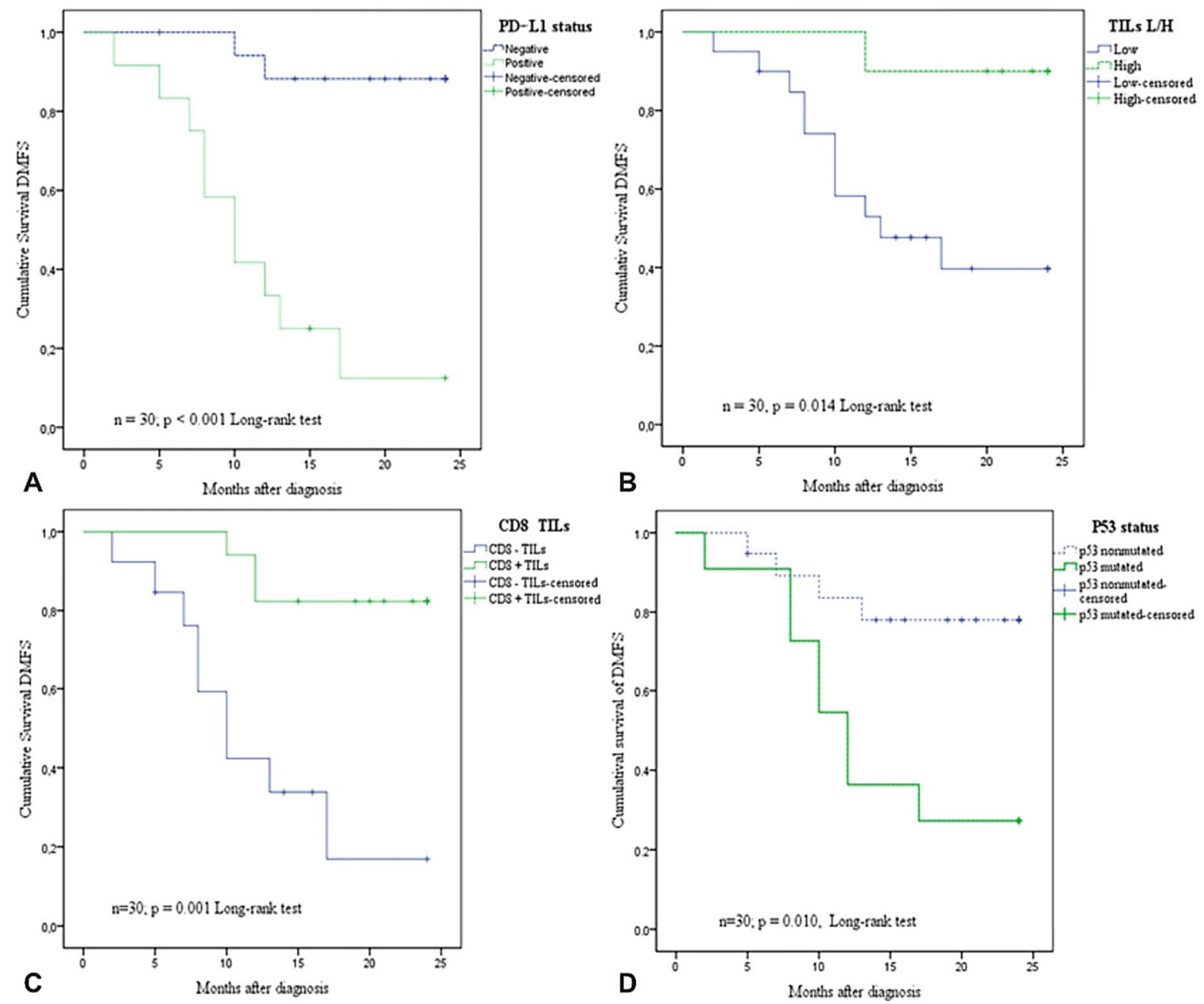

Figure 3 - Kaplan-Meier curves for DMFS analyses of TNBC patients according to PD-L1 immunoexpression (A), stTILs level (B), CD8 TILs immunoexpression (C) and p53 status (D). CD8: Cluster of differentiation 8; DMFS: Distant metastasis free survival; PD-L1: Programmed death-ligand 1; stTILs: Stromal tumor-infiltrating lymphocytes; TNBC: Triple-negative breast cancer.

All these divergent results reported in the literature lead to the necessity to further explore the role of PD-L1 immunoexpression on larger cohort for a longer period of follow-up, taking in considerations all the factors which can influence the prognosis.

Because TNBC is characterized by a highly tumor mutational burden, this leads to an enhancement of immune response and consecutively an increase levels of stTILs compared to other molecular BC subtypes [35]. The prognostic value of stTILs in TNBC was highlighted by several studies and clinical phase III trials, like FinHer trial [36] or Eastern Cooperative Oncology Group (ECOG) 2197 + ECOG 1199 [37]. Quantification of stTILs level is nowadays included in the last edition of breast tumors classification from $W H O 2019$, as a useful prognostic biomarker [12]. An increase with $10 \%$ of stTILs is associated with $15 \%$ reduced risk of relapse and $17 \%$ reduced risk of death regardless of adjuvant therapy [15]. Even if there are reports which demonstrated that high stTILs levels are more common in TNBC, still their levels varied great among tumors belonging to this BC molecular subgroup. In the present research, 33.3\% of the cases had high stTILs level, consistent with other reports which demonstrated an increased level of stTILs in previously untreated patients with TNBC [36]. Loi et al.
(2017) proved in their study that stTILs can be used as a predictive biomarker since high levels of stTILs are associated with a good response after Pembrolizumab immunotherapy (a humanized antibody which blocks PD-1 located on lymphocytes), and it is associated with an improvement of the objective response rate [36]. We also found not only that high stTILs level are associated with a better DMFS but also that there is a statistically significant association between TILs level and PD-L1 immunoexpression. In the study of Tomioka et al. (2018), it was noticed that low stTILs and high PD-L1 immunoexpression cases are characterized by the poorest DFS and OS, and it was suggested that immunotherapy should be more effective for these category of patients [32]. For these reasons, it is better both biomarkers to be evaluated and to be used together in prediction of ICIs therapy.

Not only presence of stTILs is important but also its composition. The microenvironment of a tumor is complex and different types of inflammatory cells are part of it, playing specific role in the progression of the malignant cells. A special attention had been paid to interactions between cytotoxic $\mathrm{T}$ cells $-\mathrm{CD} 8$ positive $(\mathrm{CD} 8+)$, regulatory $\mathrm{T}$ cells - CD4 positive (CD4+), and regulatory forkhead box protein P3 (FOXP3) T-cells positivity. In the systematic 
review and meta-analysis of Gao et al. (2020), it is shown that both high stTILs level and specific immunophenotype of stTILs (CD8+, CD4+ and FOXP4+) have an important prognostic value, with improvement of DFS or OS [38]. In our study, we investigated the role CD8+ TILs and its possible association with PD-L1 immunoexpression. The results proved a statistically significant association between them, consistent with other studies [38-40]. In addition, we also noted an improvement of DMFS when there is a positive immunoexpression of CD8+ TILs, confirming the importance of using CD8 as a biomarker in the stratification of patients suitable for immunotherapy.

The tumor protein p53 (TP53) gene plays an important role in carcinogenesis and its mutation is identified in almost $80 \%$ of TNBC cases [22, 41]. There have been identified two types of TP53 mutations, which leads to an aberrant $\mathrm{p} 53$ protein immunoexpression: those which are involving the protein-encoding reading frame and have as result an absence of p53 protein immunoexpression ("null-type" mutations), and "missense" mutations with an "overexpression" for p53 protein [42]. Consistent with data from literature, we also demonstrated that an aberrant p53 immunoexpression has a prognostic value since its presence is associated with a worse DMFS. The mutant p53 protein acquired more functions than the "wild-type" p53 protein (normal immunoexpression) and can trigger the immune system by expressing itself on the tumor cell surface through histocompatibility complex (neoantigen) [22, 43, 44]. It was also demonstrated that mutation of TP53 gene can lead to a poor reaction of CD8+ T-cells, which can affect the response to the immunotherapy [45]. In our cohort, we identified six cases with overexpression of $\mathrm{p} 53,85.7 \%$ of them being also positive for CD8 TILs, in concordance with the study of Lee et al. (2019), which demonstrated that "missense" mutations of TP53 gene can trigger a highly immunological response different from the "null-type" mutations of TP53 in TNBC. So, even TNBC are frequently associated with a good immunological response, still these patients can be further stratified by stTILs and p53 immunoexpression because these potential biomarkers can predict a better response to adjuvant therapy. Study of Lee et al. (2019) on 798 of TNBC cases highlighted the importance to identify those cases with aberrant p53 immunoexpression because it can also predict a good response to immunotherapy [44], and novel therapy targeting this pathway of carcinogenesis may developed [46].

\section{ㅁ Conclusions}

The present research analyzes the association between PD-L1 immunoexpression with multiple clinico-morphological features of TNBC, with the presence of stTILs and its composition, and with p53 immunoexpression. Our results bring new insights of the fine connections between tumor microenvironment and molecular changes and help us to better understand these highly aggressive tumors to identify the more useful biomarkers for predicting the response to adjuvant therapy. Testing both PD-L1 status and other factors which are correlated with PD-L1 immunoexpression can represent a method for selecting the most suitable patients for the treatment with ICIs, as monotherapy or in combination with other drugs. Our results can represent a solid base for further researches on larger group, to be able to establish the best biomarkers with predictive and prognostic role, and may lead to the outlining of a diagnostic and treatment protocol.

\section{Conflict of interests}

The authors declare that they have no conflict of interests.

\section{Authors' contributions}

Mariana Deacu and Gabriela Izabela Bălţătescu equally contributed to the manuscript.

\section{Informed consent}

The experiments were performed with prior informed consent (written) from each participant.

\section{Funding}

This work was supported by Ovidius University of Constanţa, Romania, through the grant number 5/14.11.2018.

\section{Acknowledgments}

This research was performed in the Center for Research and Development of the Morphological and Genetic Studies of Malignant Pathology from the Ovidius University of Constanţa, POSCCE 2.2.1, Project ID: 1844, code SMIS: 48750, CEDMOG, contract 627/11.03.2014.

\section{References}

[1] Bray F, Ferlay J, Soerjomataram I, Siegel RL, Torre LA, Jemal A. Global cancer statistics 2018: GLOBOCAN estimates of incidence and mortality worldwide for 36 cancers in 185 countries. CA Cancer J Clin, 2018, 68(6):394-424. https:// doi.org/10.3322/caac.21492 PMID: 30207593

[2] Perou CM, Sørlie T, Eisen MB, van de Rijn M, Jeffrey SS, Rees CA, Pollack JR, Ross DT, Johnsen H, Akslen LA, Fluge O, Pergamenschikov A, Williams C, Zhu SX, Lønning PE, Børresen-Dale AL, Brown PO, Botstein D. Molecular portraits of human breast tumours. Nature, 2000, 406(6797):747-752. https://doi.org/10.1038/35021093 PMID: 10963602

[3] Sørlie T, Perou CM, Tibshirani R, Aas T, Geisler S, Johnsen H, Hastie T, Eisen MB, van de Rijn M, Jeffrey SS, Thorsen T, Quist H, Matese JC, Brown PO, Botstein D, Lønning PE, Børresen-Dale AL. Gene expression patterns of breast carcinomas distinguish tumor subclasses with clinical implications. Proc Natl Acad Sci U S A, 2001, 98(19):10869-10874. https://doi.org/10.1073/pnas.191367098 PMID: 11553815 PMCID: PMC58566

[4] Goldhirsch A, Winer EP, Coates AS, Gelber RD, PiccartGebhart M, Thürlimann B, Senn HJ; Panel Members. Personalizing the treatment of women with early breast cancer: highlights of the St Gallen International Expert Consensus on the Primary Therapy of Early Breast Cancer 2013. Ann Oncol, 2013, 24(9):2206-2223. https://doi.org/10.1093/ann onc/mdt303 PMID: 23917950 PMCID: PMC3755334

[5] Livasy CA. Pathologic evaluation of triple-negative breast cancer. In: Tan AR (ed). Triple-negative breast cancer: a clinician's guide. Springer International Publishing AG, Cham, 2018, 1-22. https://doi.org/10.1007/978-3-319-69980-6 1

[6] Denkert C, von Minckwitz G, Darb-Esfahani S, Lederer B, Heppner BI, Weber KE, Budczies J, Huober J, Klauschen F, Furlanetto J, Schmitt WD, Blohmer JU, Karn T, Pfitzner BM, Kümmel S, Engels K, Schneeweiss A, Hartmann A, Noske A, Fasching PA, Jackisch C, van Mackelenbergh M, Sinn P, Schem C, Hanusch C, Untch M, Loibl S. Tumour-infiltrating lymphocytes and prognosis in different subtypes of breast cancer: a pooled analysis of 3771 patients treated with neoadjuvant therapy. Lancet Oncol, 2018, 19(1):40-50. https:// doi.org/10.1016/S1470-2045(17)30904-X PMID: 29233559

[7] Pruneri G, Vingiani A, Bagnardi V, Rotmensz N, De Rose A, Palazzo A, Colleoni AM, Goldhirsch A, Viale G. Clinical validity of tumor-infiltrating lymphocytes analysis in patients with triple-negative breast cancer. Ann Oncol, 2016, 27(2):249256. https://doi.org/10.1093/annonc/mdv571 PMID: 26598540 
[8] Pruneri G, Gray KP, Vingiani A, Viale G, Curigliano G Criscitiello C, Láng I, Ruhstaller T, Gianni L, Goldhirsch A, Kammler R, Price KN, Cancello G, Munzone E, Gelber RD, Regan MM, Colleoni M. Tumor-infiltrating lymphocytes (TILs) are a powerful prognostic marker in patients with triplenegative breast cancer enrolled in the IBCSG phase III randomized clinical trial 22-00. Breast Cancer Res Treat, 2016, 158(2):323-331. https://doi.org/10.1007/s10549-0163863-3 PMID: 27372069 PMCID: PMC4977583

[9] Kwa MJ, Adams S. Checkpoint inhibitors in triple-negative breast cancer (TNBC): where to go from here. Cancer, 2018, 124(10):2086-2103. https://doi.org/10.1002/cncr.31272 PMID: 29424936

[10] Keir ME, Liang SC, Guleria I, Latchman YE, Qipo A, Albacker LA, Koulmanda M, Freeman GJ, Sayegh MH, Sharpe AH. Tissue expression of PD-L1 mediates peripheral T cell tolerance. J Exp Med, 2006, 203(4):883-895. https://doi.org/10.1084/jem.20 051776 PMID: 16606670 PMCID: PMC2118286

[11] Schmid P, Adams S, Rugo HS, Schneeweiss A, Barrios $\mathrm{CH}$, Iwata H, Diéras V, Hegg R, Im SA, Shaw Wright G, Henschel V, Molinero L, Chui SY, Funke R, Husain A, Winer EP, Loi S, Emens LA; IMpassion130 Trial Investigators. Atezolizumab and Nab-Paclitaxel in advanced triple-negative breast cancer. N Engl J Med, 2018, 379(22):2108-2121. https://doi.org/10. 1056/NEJMoa1809615 PMID: 30345906

[12] World Health Organization (WHO) Classification of Tumours Editorial Board. Breast tumours. $5^{\text {th }}$ edition, vol. 2, WHO Classification of Tumours Series, International Agency for Research on Cancer (IARC) Press, Lyon, France, 2019. https://publications.iarc.fr/581

[13] Salgado R, Denkert C, Demaria S, Sirtaine N, Klauschen F, Pruneri G, Wienert $S$, Van den Eynden G, Baehner FL, Penault-Llorca F, Perez EA, Thompson EA, Symmans WF, Richardson AL, Brock J, Criscitiello C, Bailey $\mathrm{H}$, Ignatiadis $\mathrm{M}$ Floris G, Sparano J, Kos Z, Nielsen T, Rimm DL, Allison KH, Reis-Filho JS, Loibl S, Sotiriou C, Viale G, Badve S, Adams S, Willard-Gallo K, Loi S; International TILs Working Group 2014. The evaluation of tumor-infiltrating lymphocytes (TILs) in breast cancer: recommendations by an International TILs Working Group 2014. Ann Oncol, 2015, 26(2):259-271. https://doi.org/ 10.1093/annonc/mdu450 PMID: 25214542 PMCID: PMC 6267863

[14] Dieci MV, Radosevic-Robin N, Fineberg S, van den Eynden G, Ternes N, Penault-Llorca F, Pruneri G, D'Alfonso TM, Demaria S, Castaneda C, Sanchez J, Badve S, Michiels S, Bossuyt V, Rojo F, Singh B, Nielsen T, Viale G, Kim SR, Hewitt S, Wienert S, Loibl S, Rimm D, Symmans F, Denkert C Adams S, Loi S, Salgado R; International Immuno-Oncology Biomarker Working Group on Breast Cancer. Update on tumorinfiltrating lymphocytes (TILs) in breast cancer, including recommendations to assess TILs in residual disease after neoadjuvant therapy and in carcinoma in situ: a Report of the International Immuno-Oncology Biomarker Working Group on Breast Cancer. Semin Cancer Biol, 2018, 52(Pt 2):1625. https://doi.org/10.1016/j.semcancer.2017.10.003 PMID: 29024776

[15] Loi S, Sirtaine N, Piette F, Salgado R, Viale G, Van Eenoo F, Rouas G, Francis P, Crown JP, Hitre E, de Azambuja E, Quinaux E, Di Leo A, Michiels S, Piccart MJ, Sotiriou C. Prognostic and predictive value of tumor-infiltrating lymphocytes in a phase III randomized adjuvant breast cancer trial in nodepositive breast cancer comparing the addition of Docetaxel to Doxorubicin with Doxorubicin-based chemotherapy: BIG 02-98. J Clin Oncol, 2013, 31(7):860-867. https://doi.org/10. 1200/JCO.2011.41.0902 PMID: 23341518

[16] Wolff AC, Hammond MEH, Allison KH, Harvey BE, Mangu PB, Bartlett JMS, Bilous M, Ellis IO, Fitzgibbons $P$, Hanna W, Jenkins RB, Press MF, Spears PA, Vance GH, Viale G, McShane LM, Dowsett M. Human epidermal growth factor receptor 2 testing in breast cancer: American Society of Clinical Oncology/College of American Pathologists Clinical Practice Guideline Focused Update. Clin Oncol, 2018, 36(20): 2105-2122. https://doi.org/10.1200/JCO.2018.77.8738 PMID: 29846122

[17] Yuan C, Liu Z, Yu Q, Wang X, Bian M, Yu Z, Yu J. Expression of PD-1/PD-L1 in primary breast tumours and metastatic axillary lymph nodes and its correlation with clinicopathological parameters. Sci Rep, 2019, 9(1):14356. https://doi.org/10.1038/s41598-019-50898-3 PMID: 31591439 PMCID: PMC6779893

[18] Hou Y, Nitta H, Wei L, Banks PM, Lustberg M, Wesolowski R, Ramaswamy B, Parwani AV, Li Z. PD-L1 expression and CD8-positive $T$ cells are associated with favorable survival in HER2-positive invasive breast cancer. Breast J, 2018, 24(6): 911-919. https://doi.org/10.1111/tbj.13112 PMID: 30230111 PMCID: PMC6724200

[19] Lee SK, Bae SY, Lee JH, Lee HC, Yi H, Kil WH, Lee JE, Kim SW, Nam SJ. Distinguishing low-risk luminal A breast cancer subtypes with $\mathrm{Ki}-67$ and p53 is more predictive of long-term survival. PLoS One, 2015, 10(8):e0124658. https:// doi.org/10.1371/journal.pone.0124658 PMID: 26241661 PMCID: PMC4524613

[20] Darb-Esfahani S, Denkert C, Stenzinger A, Salat C, Sinn B, Schem C, Endris V, Klare P, Schmitt W, Blohmer JU, Weichert W, Möbs M, Tesch H, Kümmel S, Sinn P, Jackisch C, Dietel M, Reimer T, Loi S, Untch M, von Minckwitz G, Nekljudova V, Loibl S. Role of TP53 mutations in triple negative and HER2-positive breast cancer treated with neoadjuvant anthracycline/taxane-based chemotherapy. Oncotarget, 2016, 7(42):67686-67698. https://doi.org/10.18632/oncotarget.11891 PMID: 27611952 PMCID: PMC5356512

[21] Coates AS, Winer EP, Goldhirsch A, Gelber RD, Gnant M, Piccart-Gebhart M, Thürlimann B, Senn HJ; Panel Members. Tailoring therapies - improving the management of early breast cancer: St. Gallen International Expert Consensus on the Primary Therapy of Early Breast Cancer 2015. Ann Oncol, 2015, 26(8):1533-1546. https://doi.org/10.1093/annonc/mdv 221 PMID: 25939896 PMCID: PMC4511219

[22] Zeng Y, Wang CL, Xian J, Ye Q, Qin X, Tan YW, Cao YD. Positive correlation between programmed death ligand-1 and p53 in triple-negative breast cancer. Onco Targets Ther, 2019, 12:7193-7201. https://doi.org/10.2147/OTT.S209484 PMID: 31564903 PMCID: PMC6731959

[23] Shen X, Zhang L, Li J, Li Y, Wang Y, Xu ZX. Recent findings in the regulation of programmed death ligand 1 expression. Front Immunol, 2019, 10:1337. https://doi.org/10.3389/fim mu.2019.01337 PMID: 31258527 PMCID: PMC6587331

[24] Blackley EF, Loi S. Targeting immune pathways in breast cancer: review of the prognostic utility of TILs in early stage triple negative breast cancer (TNBC). Breast, 2019, 48(Suppl 1): S44-S48. https://doi.org/10.1016/ S0960-9776(19)31122-1 PMID: 31839159

[25] Couzin-Frankel J. Breakthrough of the year 2013. Cancer immunotherapy. Science, 2013, 342(6165):1432-1433. https:// doi.org/10.1126/science.342.6165.1432 PMID: 24357284

[26] Emens LA, Loi S, Rugo HS, Schneeweiss A, Diéras V, Iwata H, Barrios CH, Nechaeva M, Molinero L, Nguyen Duc A, Funke R, Chui SY, Husain A, Winer EP, Adams S, Schmid P. Abstract GS1-04: IMpassion130: Efficacy in immune biomarker subgroups from the global, randomized, double-blind, placebo-controlled, phase III study of Atezolizumab $+\mathrm{Nab}$-Paclitaxel in patients with treatment-naïve, locally advanced or metastatic triplenegative breast cancer. Proceedings of the 2018 San Antonio Breast Cancer Symposium, 2018 December 4-8, San Antonio, TX, American Association for Cancer Research (AACR), Philadelphia (PA), USA, Cancer Res, 2019, 79(4 Suppl): Abstract GS1-04. https://doi.org/10.1158/1538-7445.SABC S18-GS1-04

[27] Shao B, Li CW, Lim SO, Sun L, Lai YJ, Hou J, Liu C, Chang CW, Qiu Y, Hsu JM, Chan LC, Zha Z, Li H, Hung MC. Deglycosylation of PD-L1 by 2-deoxyglucose reverses PARP inhibitorinduced immunosuppression in triple-negative breast cancer. Am J Cancer Res, 2018, 8(9):1837-1846. PMID: 30323975 PMCID: PMC6176188

[28] Cozaru GC, Mitroi AF, Aschie M, Brinzan CS, Poinareanu I. E-P12.16: Her2 gene status in breast "in situ" and invasive ductal carcinoma. Abstracts from the $50^{\text {th }}$ European Society of Human Genetics Conference: Electronic Posters. Eur J Hum Genet, 2019, 26(Suppl 1):968-969. https://doi.org/10. 1038/s41431-018-0248-6

[29] Doğukan R, Uçak R, Doğukan FM, Tanık C, Çitgez B, Kabukcuoğlu F. Correlation between the expression of PD$\mathrm{L} 1$ and clinicopathological parameters in triple negative breast cancer patients. Eur J Breast Health, 2019, 15(4):235-241. https://doi.org/10.5152/ejbh.2019.4912 PMID: 31620682 PMCID: PMC6776123 
[30] Mittendorf EA, Philips AV, Meric-Bernstam F, Qiao N, Wu Y, Harrington S, Su X, Wang Y, Gonzalez-Angulo AM, Akcakanat A, Chawla A, Curran M, Hwu P, Sharma P, Litton JK, Molldrem JJ, Alatrash G. PD-L1 expression in triple-negative breast cancer. Cancer Immunol Res, 2014, 2(4):361-370. https://doi.org/ 10.1158/2326-6066.CIR-13-0127 PMID: 24764583 PMCID: PMC4000553

[31] Muenst S, Schaerli AR, Gao F, Däster S, Trella E, Droeser RA, Muraro MG, Zajac P, Zanetti R, Gillanders WE, Weber WP Soysal SD. Expression of programmed death ligand 1 (PD-L1) is associated with poor prognosis in human breast cancer. Breast Cancer Res Treat, 2014, 146(1):15-24. https://doi. org/10.1007/s10549-014-2988-5 PMID: 24842267 PMCID: PMC4180714

[32] Tomioka N, Azuma M, Ikarashi M, Yamamoto M, Sato M Watanabe KI, Yamashiro K, Takahashi M. The therapeutic candidate for immune checkpoint inhibitors elucidated by the status of tumor-infiltrating lymphocytes (TILs) and programmed death ligand 1 (PD-L1) expression in triple negative breast cancer (TNBC). Breast Cancer, 2018, 25(1):34-42. https:// doi.org/10.1007/s12282-017-0781-0 PMID: 28488168

[33] Schmolze D, Behrendt C, Lee PP, Apple S. The prognostic value of PD-L1 expression in triple-negative breast cancer: a cohort study and systematic literature review. Pathol Lab Med Open J, 2019, 1(1):37-44. https://doi.org/10.17140/ PLMOJ-1-107 https://openventio.org/wp-content/uploads/ThePrognostic-Value-of-Pd-L1-Expression-in-Triple-NegativeBreast-Cancer-A-Cohort-Study-and-Systematic-LiteratureReview-PLMOJ-1-107.pdf

[34] Lee J, Kim DM, Lee A. Prognostic role and clinical association of tumor-infiltrating lymphocyte, programmed death ligand-1 expression with neutrophil-lymphocyte ratio in locally advanced triple-negative breast cancer. Cancer Res Treat, 2019 51(2):649-663. https://doi.org/10.4143/crt.2018.270 PMID: 30064200 PMCID: PMC6473269

[35] Planes-Laine G, Rochigneux P, Bertucci F, Chrétien AS Viens P, Sabatier R, Gonçalves A. PD-1/PD-L1 targeting in breast cancer: the first clinical evidences are emerging. A literature review. Cancers (Basel), 2019, 11(7):1033. https://doi.org/10.3390/cancers11071033 PMID: 31336685 PMCID: PMC6679223

[36] Loi S, Adams S, Schmid P, Cortés J, Cescon DW, Winer EP, Toppmeyer DL, Rugo HS, De Laurentiis M, Nanda R, Iwata H, Awada A, Tan A, Wang A, Aktan G, Karantza V, Salgado R. Relationship between tumor infiltrating lymphocyte (TIL) levels and response to Pembrolizumab (Pembro) in metastatic triplenegative breast cancer (mTNBC): results from KEYNOTE086. Ann Oncol, 2017, 28(Suppl 5):V608. https://doi.org/10. 1093/annonc/mdx440.005

[37] Adams S, Gray RJ, Demaria S, Goldstein L, Perez EA Shulman LN, Martino S, Wang M, Jones VE, Saphner TJ, Wolff AC, Wood WC, Davidson NE, Sledge GW, Sparano JA, Badve SS. Prognostic value of tumor-infiltrating lymphocytes in triple-negative breast cancers from two phase III randomized adjuvant breast cancer trials: ECOG 2197 and ECOG 1199. J Clin Oncol, 2014, 32(27):2959-2966. https://doi.org/10. 1200/JCO.2013.55.0491 PMID: 25071121 PMCID: PMC 4162494

[38] Gao G, Wang Z, Qu X, Zhang Z. Prognostic value of tumorinfiltrating lymphocytes in patients with triple-negative breast cancer: a systematic review and meta-analysis. BMC Cancer, 2020, 20(1):179. https://doi.org/10.1186/s12885-020-6668-z PMID: 32131780 PMCID: PMC7057662

[39] Vihervuori H, Autere TA, Repo H, Kurki S, Kallio L, Lintunen MM, Talvinen $\mathrm{K}$, Kronqvist $\mathrm{P}$. Tumor-infiltrating lymphocytes and $\mathrm{CD}^{+} \mathrm{T}$ cells predict survival of triple-negative breast cancer. J Cancer Res Clin Oncol, 2019, 145(12):3105-3114. https:// doi.org/10.1007/s00432-019-03036-5 PMID: 31562550 PMCID: PMC6861359

[40] Matsumoto $\mathrm{H}$, Thike AA, Li H, Yeong J, Koo SL, Dent RA, Tan $\mathrm{PH}$, Iqbal J. Increased CD4 and CD8-positive T cell infiltrate signifies good prognosis in a subset of triple-negative breast cancer. Breast Cancer Res Treat, 2016, 156(2):237247. https://doi.org/10.1007/s10549-016-3743-x PMID: 26960711

[41] Li JP, Zhang XM, Zhang Z, Zheng LH, Jindal S, Liu YJ. Association of p53 expression with poor prognosis in patients with triple-negative breast invasive ductal carcinoma. Medicine (Baltimore), 2019, 98(18):e15449. https://doi.org/10.1097/MD. 0000000000015449 PMID: 31045815 PMCID: PMC6504250

[42] Oros Klein K, Oualkacha K, Lafond MH, Bhatnagar S, Tonin PN, Greenwood CM. Gene coexpression analyses differentiate networks associated with diverse cancers harboring TP53 missense or null mutations. Front Genet, 2016, 7:137. https:// doi.org/10.3389/fgene.2016.00137 PMID: 27536319 PMCID: PMC4971393

[43] Mihalcea CE, Moroşanu AM, Murăraşu D, Puiu L, Cinca SA, Voinea SC, Mirancea N. Analysis of TP53 gene and particular infrastructural alterations in invasive ductal mammary carcinoma. Rom J Morphol Embryol, 2020, 61(2):441-447. https://doi.org/ 10.47162/RJME.61.2.13 PMID: 33544795 PMCID: PMC 7864295

[44] Lee M, Park IA, Heo SH, Kim YA, Gong G, Lee HJ. Association between p53 expression and amounts of tumor-infiltrating lymphocytes in triple-negative breast cancer. J Pathol Transl Med, 2019, 53(3):180-187. https://doi.org/10.4132/jptm.2019. 02.08 PMID: 30853706 PMCID: PMC6527934

[45] Braun MW, Iwakuma T. Regulation of cytotoxic T-cell responses by p53 in cancer. Trans Cancer Res, 2016, 5(6):692-697. https://doi.org/10.21037/tcr.2016.11.76 PMID: 28944167 PMCID: PMC5607642

[46] Cao X, Hou J, An Q, Assaraf YG, Wang X. Towards the overcoming of anticancer drug resistance mediated by $p 53$ mutations. Drug Resist Updat, 2019, 49:100671. https://doi. org/10.1016/j.drup.2019.100671 PMID: 31841768

\section{Corresponding authors}

Liliana-Ana Tuţă, Professor, MD, PhD, Department of Nephrology, Sf. Apostol Andrei Emergency County Hospital, Constanţa; Department of Nephrology, Faculty of Medicine, Ovidius University of Constanţa, 145 Tomis Avenue, 900591 Constanţa, Romania; Phone +40722-300 505, Fax +40241-662 071, e-mail: tutaliliana@yahoo.com

Gabriela Izabela Bălţătescu, MD, PhD, Clinical Service of Pathology, Sf. Apostol Andrei Emergency County Hospital, Constanţa; Center for Research and Development of the Morphological and Genetic Studies of Malignant Pathology (CEDMOG), Ovidius University of Constanţa, 1 Universităţii Lane, 900470 Constanţa, Romania; Phone +40241605 002, e-mail: gabrielabaltatescu@yahoo.com 